\title{
Staging Bipolar Disorder
}

\author{
Eduard Vieta $\cdot$ M. Reinares $\cdot$ A. R. Rosa
}

Received: 11 November 2009/Revised: 16 March 2010/Accepted: 30 April 2010/Published online: 12 May 2010

(C) Springer Science+Business Media, LLC 2010

\begin{abstract}
The purpose of this study was to analyze the evidence supporting a staging model for bipolar disorder. The authors conducted an extensive Medline and Pubmed search of the published literature using a variety of search terms (staging, bipolar disorder, early intervention) to find relevant articles, which were reviewed in detail. Only recently specific proposals have been made to apply clinical staging to bipolar disorder. The staging model in bipolar disorder suggests a progression from prodromal (at-risk) to more severe and refractory presentations (Stage IV). A staging model implies a longitudinal appraisal of different aspects: clinical variables, such as number of episodes and subsyndromal symptoms, functional and cognitive impairment, comorbidity, biomarkers, and neuroanatomical changes. Staging models are based on the fact that response to treatment is generally better when it is introduced early in the course of the illness. It assumes that earlier stages have better prognosis and require simpler therapeutic regimens. Staging may assist in bipolar disorder treatment planning and prognosis, and emphasize the importance of early intervention. Further research is required in this exciting and novel area.
\end{abstract}

Keywords Staging $\cdot$ Bipolar disorder $\cdot$ Early intervention

E. Vieta $(\bowtie) \cdot$ M. Reinares · A. R. Rosa

Bipolar Disorders Program, Institute of Neuroscience,

Hospital Clínic Barcelona, University of Barcelona,

IDIBAPS, CIBERSAM, Villarroel 170,

08036 Barcelona, Spain

e-mail: evieta@clinic.ub.es

\section{Introduction}

Bipolar disorder is a chronic and recurrent illness, which represents a major public health problem, and can lead to incomplete functional recovery, social/family disruptions, and cognitive impairment, in addition to increased mortality. The World Health Organization's Global Burden of Disease Study ranks bipolar disorder as the sixth cause of years lost to disability (Murray and Lopez 1997).

Although the use of clinical staging is widespread in medicine, only recently have specific proposals been made to apply clinical staging to bipolar disorder. The neglect of staging in mental disorders parallels its reliance on crosssectional descriptions rather than the longitudinal study of prodromes, the fully developed disorder and residual states (Fava and Kellner 1993). In psychiatry, in addition to augmenting categorical approaches with symptoms dimensions (Vieta and Phillips 2007), consideration needs to be given to issues such as time, severity, persistence, and recurrence; together with these aspects, biological changes and the social impact of the disorder could also be drawn into the definition to produce a clinopathological model (McGorry et al. 2008). Recently, staging has been suggested by some authors as a course specifier for DSM-V (McGorry 2007; Colom and Vieta 2009).

As suggested by McGorry (2007), a disorder that is potentially severe and which may progress if untreated is likely to be most appropriate for staging; early treatment should demonstrably increase the chance of cure or at least of reducing mortality and disability. Therefore, early treatment may change the prognosis and consequently prevent progression to subsequent stages.

The natural course of untreated bipolar disorder involves multiple recurrences, persistent symptoms, potential cognitive impairment, comorbidity, and several neurobiological 
changes. Staging models may help to clarify the mechanisms underlying the progression of the disorder and assist in treatment planning and prognosis. The staging model in bipolar disorder suggests a progression from prodromal to more severe and refractory presentations, highlighting the relevance of early intervention. Furthermore, early intervention is usually related to a better response to treatment. Staging models would allow clinicians to guide prognosis and therapy according to the different stages of the illness (Berk et al. 2007a; Kapczinski et al. 2009a).

The aim of this review was to analyze the published literature about staging models for bipolar disorders and see to what extent it can help to foster early intervention strategies.

\section{Methods}

The authors conducted an extensive Medline and Pubmed search of the published English literature using terms that included bipolar disorder AND (staging OR early intervention). This search returned 142 articles or reviews between 1982 and 2009. Articles were selected based on title and abstract and, where necessary, examination of the full text to assess relevance. Most of them were excluded because their focus was not staging but other issues related to bipolar disorder. In addition, reference lists from identified articles were examined. A search for published articles written by specific authors who had been working on staging in other mental disorders was also carried out.

\section{Results}

Fifty-seven articles were included in this review. They will be divided into two main subjects: the basis for a staging model and the proposed staging models in bipolar disorder.

\section{Grounds for a Staging Model in Bipolar Disorder}

The course of bipolar disorder is not uniform, but several pharmacological (Franchini et al. 1999; Swann et al. 1999; Ketter et al. 2006) and psychological trials (Scott et al. 2006; Colom et al. in press) have shown that the earlier the intervention is implemented, the better the response to treatment. Recent data from a prospective, naturalistic cohort study showed that the duration of untreated psychosis predicted remission, positive symptoms, and social functioning at 8 years; continuing functional recovery between 4 and 8 years was predicted by duration of untreated illness (Crumlish et al. 2009). Chronicity is related to significant consequences in the patient's lives. Most authors agree that treatment delay in bipolar patients is linked with poorer social adjustment, higher number of hospitalizations, increased risk of suicide, development of comorbidities, forensic complications, and global impairment of the capacity to face developmental tasks in bipolar patients (Conus et al. 2006). Furthermore, it has been reported that the duration of euthymia shortens and the risk of subsequent recurrence increases with each new affective episode of the illness (Kessing et al. 1998, 2004). Post (1992) suggested that multiple episodes lead to permanent alterations in neuronal activity, which may be transduced at the level of a greater liability to relapse and the potentially poorer response to medication in patients with multiple episodes. Therefore, episode frequency and severity, together with an augmented sensitivity to stress factors, may increase with the passing of time or with each new recurrence (Post et al. 1986; Kapczinski et al. 2008a).

It has been reported that early- versus late-stage bipolar disorder patients differ in terms of biological markers (Kapczinski et al. 2009a). A staging model for bipolar disorder should differentiate the neurobiological correlates of the disorder's distinct stages (Berk et al. 2007a, b; Kapczinski et al. 2009a). Some biological factors such as white matter hyperintensities, with cortical lesions appear to be associated with a worse prognosis (Moore et al. 2001; Silverstone et al. 2003). Morphometric studies have demonstrated an enlargement of the third and lateral ventricles (Soares et al. 2005), reduced gray matter in the hippocampus and cerebellum (Moorhead et al. 2007), reduced volumes in some areas of the prefrontal cortex (Blumberg et al. 2006; Soares et al. 2005), and an increased size of the amygdala in patients with bipolar disorder (Blumberg et al. 2006). It has been reported that such neuroanatomical changes tend to be more pronounced with repeated episodes and correlate with length of illness (Lyoo et al. 2006; Strakowski et al. 2002). Therefore, some brain regions, such as the anterior cingulate and the ventrolateral prefrontal cortex, show morphological abnormalities in later phases of the illness that are likely related to either illness progression or to the effects of drug treatment (Salvadore et al. 2008a).

Anatomical changes could be a reflection of changes in neurotrophic factors and increased pro-apoptotic routes (Kapczinski et al. 2009b). Among those neurobiological markers that appear to be involved in the pathophysiology of bipolar disorder, the brain-derived neurotrophic factor (BDNF) has received special attention due to its role in regulating neuronal survival, structure, and function. BDNF (Cunha et al. 2006), as well as other neurotrophins such as NT3 (Walz et al. 2007), NT4 (Walz et al. 2009), and GDNF (Rosa et al. 2006) appear to be altered in bipolar disorder mood episodes. Furthermore, recent findings have showed that biochemical markers may change significantly from the early to late stages of 
bipolar disorder (Kauer-Sant'Anna et al. 2009; Andreazza et al. 2009). The TNF-alpha and IL-6 cytokines were shown to be increased in early and late stage of bipolar disorder compared to controls, whereas BDNF levels were decreased in the late but not early stage of bipolar disorder (Kauer-Sant'Anna et al. 2009). The levels of the anti-inflammatory cytokine IL-10 also declined in the late-stage disorder (Kauer-Sant'Anna et al. 2009). These and other findings (Cunha et al. 2008) indicate that patients with bipolar disorder are likely to be in a proinflammatory state (Brietzke and Kapczinski 2008; Brietzke et al. 2009), which worsens in the later stages of the illness. Some parameters of oxidative stress, such as 3-nitrotyrosine, are also altered in the early stages of bipolar disorder; while others, such as glutathione transferase (GST) and glutathione reductase (GR), differ from controls only in those patients with multiple episodes in later stages of bipolar disorder (Andreazza et al. 2009). Data also suggest that the lowering of BDNF levels in acute episodes occurs in parallel with increased oxidative stress, suggesting that such changes occur in an orchestrated fashion (Kapczinski et al. 2008b). Oxidative stress plays a key role in the induction of DNA damage, endothelial dysfunction, and telomere shortening (Kapczinski et al. 2008a). Bipolar patients presented an increase of frequency of DNA damage when compared to controls. The frequency of DNA damage correlates with the severity of symptoms of depression and mania (Andreazza et al. 2007). An accelerated aging process has been also suggested in bipolar disorder, as indicated by increased telomere shortening (Simon et al. 2006) and greater age-related decreases in BDNF levels in bipolar patients compared to controls (Yatham et al. 2009).

Taken together, these findings suggest that with multiple mood episodes and longer duration of illness, the neuroprotective mechanisms become less effective and the deleterious effects of these biological changes become more apparent. This is in accordance with the staging model of bipolar disorder and provides some support for the theory of involvement of allostatic process in bipolar patients. The term "allostatic load" refers to a cumulative, multisystem view of the physiological toll that is required for adaptation to stress. Oxidative stress, neurotrophic factors, and the immune-inflammatory system genes were identified as mediators of allostatic load. The effects of allostatic load are cumulative and most notably seen during the process of aging and acute and chronic stress. The allostatic load concept supports the theory that early intervention may promote better treatment response and clinical outcome for bipolar patients.

To sum up, early therapeutic interventions may play a neuroprotective role reducing neurobiological abnormalities linked to the illness (Vieta et al. in press). The timing of neurobiological changes suggests that the optimal period for neuroprotective interventions is either the prodromal phase or during the early stages of the illness (Salvadore et al. 2008b). There is increasing evidence that agents such as lithium and valproate have significant neuroprotective properties (Frey et al. 2006).

In addition, cognitive deficits seem to be related to the severity of the disease (Martínez-Arán et al. 2007), being more evident in patients who have experienced multiple episodes (Torres et al. 2007). Greater neuropsychological dysfunction in bipolar disorder has been associated with a worse prior course of the illness, particularly the number of manic episodes, hospitalizations, and length of illness (Robinson and Ferrier 2006), although there is a lack of prospective, longitudinal studies on this area. Deficits in memory, attention, and planning have been consistently reported in euthymic bipolar patients. Such deficits appear to be related to impairment in distinct domains of functioning (Martínez-Arán et al. 2007); memory deficits may represent a serious problem for bipolar patients with consequent effect on their work productivity as well as more difficulties in their interpersonal relationships. Significant functional impairment has been found in bipolar patients even in remission (Rosa et al. 2009). Neurocognitive symptoms can have a clinical value as they can lead to the acquisition of more information about the brain areas and functions involved in the pathogenesis of the disease, and they might also be useful as potential endophenotypes. Cognitive deficits are predictive of worse functional outcome at 4-year follow-up (Bonnín et al. in press). Both cognitive and functional impairment represent a potential target for prophylactic treatment, their assessment should be considered in clinical practice.

Other aspects that have also been related to a poor outcome are subsyndromal symptoms and psychiatric comorbidity. Particularly, subsyndromal depressive symptoms have been consistently associated with poor cognitive and occupational functioning (Rosa et al. 2009). Regarding comorbidity, those most frequently observed in bipolar disorder are substance-use disorders and anxiety disorders (McElroy et al. 2001). It is unclear whether disorders usually classified as comorbidities are truly biologically separate conditions, biologically antecedent risk markers, prodromal illness expressions, artifacts of overlapping and imperfect classification systems, or bipolar disorder subtypes (Correll et al. 2007). However, comorbidity and its negative impact could be reduced by an early diagnosis and appropriate treatment; which is not always the case in bipolar disorders.

All the factors mentioned have been considered by staging models for bipolar disorders. 
Proposed Staging Models in Bipolar Disorder

Clinical assessment added to the evaluation of psychosocial and cognitive functioning and peripheral biomarkers in the interepisodic period may offer a consistent set of data that, analyzed in the light of genomic and neuroimaging findings, may help to create a model of staging. Clinical staging in psychiatry was first proposed by Fava and Kellner (1993) and developed by the McGorry group (2006) for psychotic and severe mood disorders. Different staging models have been proposed in bipolar disorder (Berk et al. 2007b; Kapczinski et al. 2009a), although they need to be better operationalized and validated by empirical research. Berk et al. (2007b) have reported that stage of illness is a clinical descriptor that has utility in conceptualizing bipolar disorders, and for devising an individualized needs-based model. Therefore, a staging model in bipolar disorder may be constructed in parallel to therapeutic algorithms, linking stage to specific treatment needs and possible therapeutic options.

Staging highlights the importance of the identification of at-risk individuals due to early diagnosis and prompt initiation of therapy is crucial to improve outcome. Berk et al. (2007b) have suggested a model adapted from McGorry et al. (2006). The disorder begins with an at-risk, asymptomatic period, where a range of risk factors (e.g., family history, substance use) may be operating (Stage 0). Individuals begin to exhibit mild or non-specific symptoms of mood disorder (Stage 1a), and may progress to manifest the range of prodromal patterns (Stage 1b). These may culminate in a first threshold episode of illness (Stage 2), which can be of either polarity, but is more commonly depressive. This may be followed by a first relapse, either subthreshold (Stage 3a), or threshold illness (Stage 3b), followed by a subsequent pattern of remission and recurrences (Stage 3c). While some individuals may recover syndromally or symptomatically, others may have an unremitting or treatment-refractory course (Stage 4). Course and expression of illness variables, the diagnostic, and pharmacological and psychotherapeutic issues relevant to each illness stage differ substantially. There is a further impact of comorbidity, specific treatment, personality, adherence, and response to therapy. In contrast to the early phases in which the focus would be on early intervention and neuroprotective strategies, in the later stages the emphasis would be more rehabilitative treatments dealing with the disabilities of the illness. As has been suggested by Berk et al. (2009), early intervention is the critical ingredient if the promise of neuroprotection is to be actualized. Early initiation of optimal therapy similarly allows the secondary prevention of the sequelae of untreated illness including impacts on family relationships, psychosexual and vocational development, identity, and a concept of self.
The initial proposal of bipolar disorder staging put forward by Berk et al. (2007a, b) was further developed by Kapczinski et al. (2009a, b). Such a model implies a longitudinal appraisal of clinical variables as well as assessment of comorbidity, functioning, neurocognition, and biomarkers in the inter-episodic period. It suggests a progression from a latent (at-risk) period to more severe and refractory presentations engendered by cumulative exposure to acute episodes, substance abuse, life stress, and inherited vulnerability. This model emphasizes the assessment of patients in the inter-episodic period and includes a latent phase and four stages. Latent phase: individuals who present mood and anxiety symptoms and increased risk (e.g., positive family history) for developing threshold bipolar disorder, they do not show cognitive impairment but polymorphisms that confer susceptibility to the illness. Stage I: patients with bipolar disorder who present well-established periods of euthymia and absence of overt psychiatric morbidity between episodes, without cognitive impairment but high levels of TNF and 3-Nytrotyrosine as biomarkers. Stage II: patients who present rapid cycling or current axis I or II comorbidities, transient impairment and, as biomarkers, they show high levels of TNF and 3-Nytrotyrosine and lower BDNF levels. Stage III: patients who present a clinically relevant pattern of cognitive and functioning deterioration (unable to work or very impaired performance) as well as altered biomarkers (morphometric changes in brain may be persistent, high levels of TNF and 3-Nytrotyrosine and lower BDNF levels). Stage IV: patients, who show cognitive and functional impairment, are unable to live autonomously and present altered brain-scans and biomarkers (ventricular enlargement and/or white matter hyperintensities, high levels of TNF and 3-Nytrotyrosine and lower BDNF levels, increased levels of Glutathione reductase and transferase). The authors have also made some therapeutic and prognostic suggestions linked to the illness stage. Whereas in early stages mood stabilizer monotherapy or a combined treatment (pharmacological monotherapy plus psychological treatment) would be enough, complex regimens or palliative measures would be required in advanced stages. Staging facilitates understanding the mechanisms underlying progression of the disorder, assists in treatment planning and prognosis, and finally, underscores the imperative for early intervention. This understanding additionally identifies the first illness episode as a critical target for early intervention, creating the hope of being able to prevent some of the neuroanatomical, neuropsychological, clinical and functional consequences of the illness (Kapczinski et al. 2009b).

Based on the criteria proposed by Kapczinski et al. (2009a) and focused on clinical and functioning factors, Reinares et al. (2010) carried out a post-hoc analysis of a 
controlled-randomized study on psychoeducation delivered to caregivers of bipolar patients. For the purpose of this study, the bipolar sample was divided into two groups (Stage I, and Stages II, III, and IV taken together). Psychoeducation for caregivers of bipolar patients on Stage I showed improvement in long-term outcome regarding time to recurrence, highlighting the importance of early intervention as some treatments can be especially useful in patients with lower severity. Future studies should contribute to the validation of the staging models as a way to help to guide treatment selection and prognosis.

A recent study concluded that clinical staging might be a useful approach to refine the early diagnosis and facilitate research into the evolution of bipolar disorder in subjects at familial risk (Duffy et al. 2010). Since some patients with bipolar disorder lack a first-degree relative with the illness, it has been suggested that early detection of individuals at risk for bipolar disorder should combine genetic, endophenotypic, and clinical methods (Correll et al. 2007). The great majority of individuals experienced a symptomatic prodromal phase prior to the first episode; however, for the identification of individuals in subsyndromal or attenuated symptoms, it is still an under-researched area that could be improved by the development of rating tools that could be introduced systematically in primary care, paying special attention to young people. A better understanding of the factors that influence progression from one stage to the next is also needed, as they may respond to therapeutic interventions.

\section{Conclusions}

The analysis of the current scientific literature supports the statement that a clinical staging model may help to validate or redefine clinical boundaries, distinguish true pathophysiology from epiphenomena or sequelae, and enable much existing data to be better understood (McGorry 2007). Although different staging models have been proposed in bipolar disorder, they need to be better operationalized and validated by empirical research. So far, most of the available evidence supporting the potential use of staging in the field of bipolar illness comes from the clinical arena and seems consistent with neurocognitive, biochemical, as well as neuroimaging findings. However, there is only evidence for differences between patients at relatively early stages versus late stages (characterized by chronicity and high-allostatic load), but not for a greater number of stages with specific therapeutic implications. Hence, it seems too early to include staging as a potential course specifier in the forecoming new editions of diagnostic systems, but its use may help to raise awareness on the need to shorten the time since illness onset on one hand, and diagnosis and effective treatment, on the other. Early intervention in bipolar disorders depends on the ability to identify individuals at high risk for developing the illness. A model of staging might not only help to predict response to treatment but also general outcome measures, such as the level of functioning and autonomy. In the near future, several models of staging should be tested and validated in the context of epidemiological studies, underlying neurobiology, and clinical trials. The staging model may become a useful way to bridge the gap between traditional evidence-based medicine and personalized medicine in the area of bipolar disorder.

Acknowledgments The authors of this study would like to thank the support of the Spanish Ministry of Science and Innovation, Instituto de Salud Carlos III, CIBERSAM, and the support of the Generalitat de Catalunya to the Bipolar Disorders Group (2009 SGR 1022). They would also like to thank the support of the Spanish Ministry of Science and Innovation, through a "Juan de la Cierva" postdoctoral contract (JCI-2009-04329).

\section{References}

Andreazza AC, Frey BN, Erdtmann B, Salvador M, Rombaldi F, Santin A, Gonçalves CA, Kapczinski F (2007) DNA damage in bipolar disorder. Psychiatry Res 53:27-32

Andreazza AC, Kapczinski F, Kauer-Sant'Anna M, Walz JC, Bond DJ, Gonçalves CA, Young LT, Yatham LN (2009) 3-Nitrotyrosine and glutathione and glutathione antioxidant system in patients in the early and late stages of bipolar disorder. Neuroscience 34:263-271

Berk M, Hallam KT, McGorry PD (2007a) The potential utility of a staging model as a course specifier: a bipolar disorder perspective. J Affect Disord 100:279-281

Berk M, Conus P, Lucas N, Hallam K, Malhi GS, Dodd S, Yatham LN, Yung A, McGorry P (2007b) Setting the stage: from prodrome to treatment resistance in bipolar disorder. Bipolar Disord 9:671-678

Berk M, Malhi GS, Hallam K, Gama CS, Dodd S, Andreazza AC, Frey BN, Kapczinski F (2009) Early intervention in bipolar disorders: clinical, biochemical and neuroimaging imperatives. J Affect Disord 114:1-13

Blumberg HP, Krystal JH, Bansal R, Martin A, Dziura J, Durkin K, Martin L, Gerard E, Charney DS, Peterson BS (2006) Age, rapid-cycling, and pharmacotherapy effects on ventral prefrontal cortex in bipolar disorder: a cross-sectional study. Biol Psychiatry 59:611-618

Bonnín CM, Martínez-Arán A, Torrent C, Pacchiarotti I, Rosa AR, Franco C, Murru A, Sanchez-Moreno J, Vieta E (in press) Clinical and neurocognitive predictors of functional outcome in bipolar euthymic patients: a long-term, follow-up study. J Affect Disord

Brietzke E, Kapczinski F (2008) TNF-alpha as a molecular target in bipolar disorder. Prog Neuropsychopharmacol Biol Psychiatry 32:1355-1361

Brietzke E, Stertz L, Fernandes BS, Kauer-Sant' anna M, Mascarenhas M, Escosteguy Vargas A, Chies JA, Kapczinski F (2009) Comparison of cytokine levels in depressed, manic and euthymic patients with bipolar disorder. J Affect Disord 116:214-217

Colom F, Vieta E (2009) The road to DSM-V: bipolar disorder episode and course specifiers. Psychopathology 42:209-218 
Colom F, Reinares M, Pachiarotti I, Mazzarini L, Martínez-Arán A, Torrent C, Rosa A, Palomino-Otiniano R, Franco C, Bonnín C, Vieta $\mathrm{E}$ (in press) Has number of previous episodes any effect on response to group psychoeducation in bipolar patients? A 5-year follow-up post-hoc analysis. Acta Neuropsychiatrica

Conus P, Berk M, McGorry PD (2006) Pharmacological treatment in the early phase of bipolar disorders: what stage are we at? Aust N Z J Psychiatry 40:199-207

Correll CU, Penzner JB, Lencz T, Auther A, Smith CW, Maalhotra AK, Kane JM, Cornblatt BA (2007) Early identification and high-risk strategies for bipolar disorder. Bipolar Disord 9:324-338

Crumlish N, Whitty P, Clarke M, Browne S, Kamali M, Gervin M, McTigue O, Kinsella A, Waddington JL, Larkin C, O'Callaghan E (2009) Beyond the critical period: longitudinal study of 8-year outcome in first-episode non-affective psychosis. Br J Psychiatry 194:18-24

Cunha AB, Frey BN, Andreazza AC, Goi JD, Rosa AR, Gonçalves CA, Santin A, Kapczinski F (2006) Serum brain-derived neurotrophic factor is decreased in bipolar disorder during depressive and manic episodes. Neurosci Lett 398:215-219

Cunha AB, Andreazza AC, Gomes FA, Frey BN, da Silveira LE, Gonçalves CA, Kapczinski F (2008) Investigation of serum highsensitive C-reactive protein levels across all mood states in bipolar disorder. Eur Arch Psychiatry Clin Neurosci 258:300-304

Duffy A, Alda M, Hajek T, Sherry SB, Grof P (2010) Early stages in the development of bipolar disorder. J Affect Disord 121:127-135

Fava GA, Kellner R (1993) Staging: a neglected dimension in psychiatric classification. Acta Psychiatr Scand 87:225-230

Franchini L, Zanardi R, Smeraldi E, Gasperini M (1999) Early onset of lithium propylaxis as a predictor of good long-term outcome. Eur Arch Psychiatry Clin Neurosci 249:227-230

Frey BN, Andreazza AC, Ceresér KM, Martins MR, Valvassori SS, Réus GZ, Quevedo J, Kapczinski F (2006) Effects of mood stabilizers on hippocampus BDNF levels in an animal model of mania. Life Sci 79:281-286

Kapczinski F, Vieta E, Andreazza AC, Frey BN, Gomes FA, Tramontina J, Kauer-Sant'anna M, Grassi-Oliveira R, Post RM (2008a) Allostatic load in bipolar disorder: implications for pathophysiology and treatment. Neurosci Biobehav Rev 32: 675-692

Kapczinski F, Frey BN, Andreazza AC, Kauer-Sant'Anna M, Cunha AB, Post RM (2008b) Increased oxidative stress as a mechanism for decreased BDNF levels in acute manic episodes. Rev Bras Psiquiatr 30:243-245

Kapczinski F, Vasco D, Kauer-Sant'Anna M, Frey BN, GrassiOliveira R, Colom F, Berk M (2009a) Clinical implications of a staging model for bipolar disorders. Expert Rev Neurother 9:957-966

Kapczinski F, Dias VV, Kauer-Sant'anna M, Brietzke E, Vázquez GH, Vieta E, Berk M (2009b) The potential use of biomarkers as an adjunctive tool for staging bipolar disorder. Prog Neuropsychopharmacol Biol Psychiatry 33:1366-1371

Kauer-Sant'Anna M, Kapczinski F, Andreazza AC, Bond DJ, Lam RW, Young LT, Yatham LN (2009) Brain derived neurotrophic factor and inflammatory markers in patients with early- vs. late stage bipolar disorder. Int J Neuropsychopharmacol 12:447-458

Kessing LV, Mortensen PB, Bolwig TG (1998) Clinical definitions of sensitisation in affective disorder: a case register study of prevalence and prediction. J Affect Disord 47:31-39

Kessing LV, Hansen MG, Andersen PK, Angst J (2004) The predictive effect of episodes on the risk of recurrence in depressive and bipolar disorders-a life-long perspective. Acta Psychiatr Scand 109:339-344

Ketter TA, Houston JP, Adams DH, Risser RC, Meyers AL, Williamson DJ, Tohen M (2006) Differential efficacy of olanzapine and lithium in preventing manic or mixed recurrence in patients with bipolar I disorder based on number of previous manic or mixed episodes. J Clin Psychiatry 67:95-101

Lyoo IK, Sung YH, Dager SR, Friedman SD, Lee JY, Kim SJ, Kim N, Dunner DL, Renshaw PF (2006) Regional cerebral cortical thinning in bipolar disorder. Bipolar Disord 8:65-74

Martínez-Arán A, Vieta E, Torrent C, Sanchez-Moreno J, Goikolea JM, Salamero M, Malhi GS, Gonzalez-Pinto A, Daban C, Alvarez-Grandi S, Fountoulakis K, Kaprinis G, Tabares-Seisdedos R, Ayuso-Mateos JL (2007) Functional outcome in bipolar disorder: the role of clinical and cognitive factors. Bipolar Disord 9:103-113

McElroy SL, Altshuler LL, Suppes T, Keck PE Jr, Frye MA, Denicoff KD, Nolen WA, Kupka RW, Leverich GS, Rochussen JR, Rush AJ, Post RM (2001) Axis I psychiatric comorbidity and its relationship to historical illness variables in 288 patients with bipolar disorder. Am J Psychiatry 158:420-426

McGorry PD (2007) Issues for DSM-V: clinical staging: a heuristic pathway to valid nosology and safer, more effective treatment in psychiatry. Am J Psychiatry 164:859-860

McGorry PD, Hickie IB, Yung AR, Pantelis C, Jackson HJ (2006) Clinical staging of psychiatric disorders: a heuristic framework for choosing earlier, safer and more effective interventions. Aust N Z J Psychiatry 40:616-622

McGorry PD, Killackey E, Yung A (2008) Early intervention in psychosis: concepts, evidence and future directions. World Psychiatry 7:148-156

Moore PB, Shepherd DJ, Eccleston D, Macmillan IC, Goswami U, McAllister VL, Ferrier IN (2001) Cerebral white matter lesions in bipolar affective disorder: relationship to outcome. $\mathrm{Br} \mathrm{J}$ Psychiatry 178:172-176

Moorhead TW, McKirdy J, Sussmann JE, Hall J, Lawrie SM, Johnstone EC, McIntosh AM (2007) Progressive gray matter loss in patients with bipolar disorder. Biol Psychiatry 62:894-900

Murray CJ, Lopez AD (1997) Global mortality, disability, and the contribution of risk factors: Global Burden of Disease Study. Lancet 349:1436-1442

Post RM (1992) Transduction of psychosocial stress into the neurobiology of recurrent affective disorder. Am J Psychiatry 149:999-1010

Post RM, Rubinow DR, JC Ballenger (1986) Conditioning and sensitization in the longitudinal course of affective illness. Br J Psychiatry 149:191-201

Reinares M, Colom F, Rosa AR, Bonnín CM, Franco C, Solé B, Kapczinski F, Vieta E (2010) The impact of staging bipolar disorder on treatment outcome of family psychoeducation. J Affect Disord 123:81-86

Robinson LJ, Ferrier IN (2006) Evolution of cognitive impairment in bipolar disorder: a systematic review of cross-sectional evidence. Bipolar Disord 8:103-116

Rosa AR, Frey BN, Andreazza AC, Ceresér KM, Cunha AB, Quevedo J, Santin A, Gottfried C, Gonçalves CA, Vieta E, Kapczinski F (2006) Increased serum glial cell line-derived neurotrophic factor immunocontent during manic and depressive episodes in individuals with bipolar disorder. Neurosci Lett 407:146-150

Rosa AR, Reinares M, Franco C, Comes M, Torrent C, SánchezMoreno J, Martínez-Arán A, Salamero M, Kapczinski F, Vieta E (2009) Clinical predictors of functional outcome of bipolar patients in remission. Bipolar Disord 11:401-409

Salvadore G, Drevets WC, Henter ID, Zarate CA, Manji HK (2008a) Early intervention in bipolar disorder, part $\mathrm{I}$ : clinical and imaging findings. Early Interv Psychiatry 2:122-135

Salvadore G, Drevets WC, Henter ID, Zarate CA, Manji HK (2008b) Early intervention in bipolar disorder, part II: therapeutics. Early Interv Psychiatry 2:136-146

Scott J, Paykel E, Morriss R, Bentall R, Kinderman P, Johnson T, Abbott R, Hayhurst H (2006) Cognitive-behavioural therapy for 
severe and recurrent bipolar disorders: randomised controlled trial. Br J Psychiatry 188:310-320

Silverstone T, McPherson H, Li Q, Doyle T (2003) Deep white matter hyperintensities in patients with bipolar depression, unipolar depression and age-matched control subjects. Bipolar Disord 5:53-57

Simon NM, Smoller JW, McNamara KL, Maser RS, Zalta AK, Pollack MH, Nierenberg AA, Fava M, Wong KK (2006) Telomere shortening and mood disorders: preliminary support for a chronic stress model of accelerated aging. Biol Psychiatry 60:432-435

Soares JC, Kochunov P, Monkul ES, Nicoletti MA, Brambilla P, Sassi RB, Mallinger AG, Frank E, Kupfer DJ, Lancaster J, Fox P (2005) Structural brain changes in bipolar disorder using deformation field morphometry. Neuroreport 16:541-544

Strakowski SM, DelBello MP, Zimmerman ME, Getz GE, Mills NP, Ret J, Shear P, Adler CM (2002) Ventricular and periventricular structural volumes in first- versus multiple-episode bipolar disorder. Am J Psychiatry 159:1841-1847

Swann AC, Bowden CL, Calabrese JR, Dilsaver SC, Morris DD (1999) Differential effect of number of previous episodes of affective disorder on response to lithium or divalproex in acute mania. Am J Psychiatry 156:1264-1266
Torres IJ, Boudreau VG, Yatham LN (2007) Neuropsychological functioning in euthymic bipolar disorder: a meta-analysis. Acta Psychiatr Scand Suppl (434):17-26

Vieta E, Phillips ML (2007) Deconstructing bipolar disorder: a critical review of its diagnostic validity and a proposal for DSMV and ICD-11. Schizophr Bull 33:886-892

Vieta E, Popovic D, Rosa AR, Solé B, Grande I, Frey BN, MartínezArán A, Kapczinski F (in press) The clinical implications of cognitive impairment and allostatic load in bipolar disorder. J Affect Disord

Walz JC, Andreazza AC, Frey BN, Cacilhas AA, Ceresér KM, Cunha AB, Weyne F, Stertz L, Santin A, Gonçalves CA, Kapczinski F (2007) Serum neurotrophin-3 is increased during manic and depressive episodes in bipolar disorder. Neurosci Lett 415:87-89

Walz JC, Magalhães PV, Giglio LM, Cunha AB, Stertz L, Fries GR, Andreazza AC, Kapczinski F (2009) Increased serum neurotrophin-4/5 levels in bipolar disorder. J Psychiatr Res 43:721-723

Yatham LN, Kapczinski F, Andreazza AC, Trevor Young L, Lam RW, Kauer-Sant'anna M (2009) Accelerated age-related decrease in brain-derived neurotrophic factor levels in bipolar disorder. Int J Neuropsychopharmacol 12:137-139 